\title{
An Empirical Study to Understand HR Practices Implemented by Small and Medium Enterprises at Central India
}

\author{
${ }^{1}$ Student, Shri Ramdeobaba College of Engineering and Management, Nagpur \\ ${ }^{2}$ Assistant Professor, Sinhgad Business School-Pune \\ Email: priyamankar554@gmail.com
}

\author{
Received: $20^{\text {th }}$ September 2018, Accepted: $11^{\text {th }}$ October 2018, Published: $31^{\text {st }}$ October 2018
}

\begin{abstract}
The purpose of this study is to understand the Human Resource (HR) practices implemented by Small and Medium Enterprises (SMEs). SMEs play a very important role in contributing towards Indian economy. After agricultural sector SMEs in India is the second largest sector in providing employment. This sector has employed almost 60 million people in the country. Human Resource Management is getting top priority in the Organisation. Almost all organization regardless of their size have HR Department that ensure implementation of HR policies. Traditionally HR department was to look after salaries and administration, housekeeping, time-keeping that are monotonous activities. But the role of HR has seen tremendous change in the last two decades. SMEs as an engine of growth have incorporated innovative techniques regarding Technology Transfer, Funding, Sales \& Marketing. Are they implementing innovative tools with respect to HR practices is the central theme of this paper. SMEs which are registered with District Industries Centre-Nagpur, Government of Maharashtra are identified for the current research. HR practices implemented by SMEs in Central India are identified through Questionnaire which is designed based on different functions of HR Department. Researchers have used Test of Hypothesis for Data Analysis \& Interpretation. It is found that HR practices followed are unsystematic \& haphazard in nature.
\end{abstract}

\section{Keywords}

Small and Medium Enterprises (SMEs), Human Resource (HR) Practices

\section{Introduction}

SMEs globally are recognized for their contribution to Gross Domestic Product. It provides number of advantages for any Economy. From the last five decades SMEs have emerged as a highly dynamic and vibrant sector of Indian economy. SMEs plays a vital role in Nation's development through its high contribution towards defense production, innovation and development to indigenous technology, export earnings and import substitution, training and skills development, domestic production, generating new entrepreneurs by providing knowledge, etc. There are almost three million SMEs present in India from which 42 per cent accounts for India's total export and 50 per cent accounts for industrial outputs. SMEs always played a significant role in transition of economies and work as a growth engine for every country. Also it provides greater employment opportunities at low capital cost comparatively than large industries, industrialization of rural and backward areas.

Human resource is the most dynamic asset that the organization has. Organisations have devised various strategies for attracting \& retaining the talent. An effective HR process helps to achieve overall objective of organization. Researchers and scientists finding more innovative ways and new theories for growing organizations. There are various HR practices adopted by the organization for the smooth functioning of operations. When it comes to adoption and implementation, some are traditional practices and some are modern practices. Some of the traditional practices are time keeping, salaries allocation, administration work and house-keeping. Whereas, modern practices include giving compensation \&benefits, training and development, , employee involvement, job design, etc. More recent function for HR department is to play a role of Business partner.

Committees were formed by the government of India to understand the problems of SMEs regarding all the issues they face. There were many problem related to labour issues, management issue, work-culture, equipment related issues, etc. those are the major problems of inception sickness in the organizations. Many studies are undertaken in different parts of countries to understand the HR practices and found the lack of these practices in many organizations. It is been concluded that there is a need of HR practices as important as Finance.

This study summarizes the HR practices comprising of all the 9 parameters. Human Resource Planning (HRP), entrepreneurs are aware about HRP but the need of it is realizes during the festive season when there is a dearth of the employee. To reduce shocks during crises this tool has been effectively used. Selection and Staffing is the method of managing manpower in the organization. Through Training and Development the future process of working of the employees can be improve. Training is to be provided for improving the current functioning of the organizations; it is to be done systematically. Having an organized structure of an organization is very important to carry out the functioning properly. Compensation and Benefits is used as the motivational tool for employees in the organization; which prohibit the use of money in a significant manner. To maintain the cordial relations among the labour is very essential to worked out the organizational work smoothly; there should be proper communication 
among the employees as well as among the management. The other related part of HRM is employee empowerment which gives the employees power to make their job related decisions.

Materials and MethodsIn India SMEs are protected by the government and they are also following HR practices to some extent. The contribution to the economic development by the SMEs is keeps on going. In this paper we have tried to find out different issues of the SMEs while implementing HR practices. The researchers are identifying different areas to reduce expenses, skill manpower, time saving activities, and so on.

To study the HR practices followed by the SMEs the data is collected form District Industries Centre (DIC), the standardize questionnaire is divided into nine different parameters which are as mention below:

- Human Resources Planning

- Selection and staffing

- Training and Development

- Organization/Job Design

- Compensation Benefits

- Union/Labour Relations

- Employee Communication

- Employee Assistance

- Employee Involvement

The main objectives of the research are:

1. To identify presently the Human Resources (HR) practices followed by the SMEs at Central India or not.

2. To identify the issues facing by the SMEs in Central India while implementing the best HR Practices.

For this research analysis the investigators have formulated some hypothesis, which will accept or rejected after the completion of the survey and data analysis. The research is based on the following hypothesis:

Null Hypothesis: SME are following the best HR practices in their organization.

Alternate Hypothesis: HR Practices followed by the SMEs are non-scientific and rudimentary.

Data for research was sought from District Industries Centre (DIC), file no. 31 to the file no. 38. Out of which the researchers considered only manufacturing industries as their key area of research. Industries scrutinize for this research study are all registered with the government.

The access to data was provided by DIC, the ministry of SMEs. The areas considered for research are Butibori, Hingna, Uppalwadi and Kalmeshwar. These regions are known Industrial areas. The sample previously decided to take only $10 \%$ of the total SMEs but later on after the discussion the sample of 100 SMEs is taken. There is number of industries which are scrutinized for the study from different areas.

From Uppalwadi total 104 SSI units, Hingna 271 SSI units, Kalmeshwar 44 SSI units \& Butibori 167 SSI units are considered.

The technique which is used for this study is non-probability sampling technique which is also known as nonrandom sampling method. The technique which is Quota sampling technique was also used by the researchers. The data is collected from the assigned numbers of individual organizations. Approximately $15 \%$ of sample units are taken from all the considered areas mentioned above.

Primary source of data was sought from the top-level authorities and HR heads from various industries. These were identified because the complete study is related to the HR practices in SMEs. Whereas magazines, websites, newspaper, articles, books, journals, etc. used as the secondary source of data.

\section{Results and Discussion}

There are number of Small and Middle Enterprises (SMEs) present at Central India, out of which the count of small enterprises are 6500 and the count of medium enterprises are of 499 as per the records of District Industries Centre (DIC). These Small and Medium Enterprises consist of service industries as well as manufacturing industries. The universe of the study is manufacturing industries only.

The study covers the complete topography of Central India. Only the registered SMEs have been considered for this study. Industrial region at Central India viz. Butibori, Hingna, Kalmeshwar, Uppalwadi is taken for this research study.

The Small Scale Industries considered for Hingna is 40 sample units, from Butibori 25 sample units, from Uppalwadi 16 sample units has been considered whereas from Kalmeshwar 7 sample units has been identified. The Medium scale Industries which is identified overall is of 12 sample units. In this way from all the areas there were 100 SMEs have been identified.

Organization Type: There were 44 SMEs Private Limited, 7 SMEs were public Limited, the number of proprietorship SMEs were 31 and 18 SMEs is in partnership.

Establishment Years: 18 companies started their operation during the year of 1960-200; after 2001 there were 35 SMEs started their operation and the remaining 55 SMEs started during the period of 1991-2000 i.e. the majority of the sample organizations. 
ISO Certification: Out of 100 sample organization only 22 organizations was ISO certified and 78 organizations were not ISO certified.

Number of Employees: There were 300 employees in two SMEs, 13 SMEs with the employee strength between 61-300, 50 SMEs with the employee strength of 11-60 and 35 SMEs containing employee strength of 10 employees or less than 10 employees.

The statistical analysis tool is a measure used to design research, analyzed data and then drawing the conclusion. The survey is summarized on the basis of important statistical methods those are Mean, Median, Mode and standard Deviation. The One-Sample-Z-Test has been used to test the Hypothesis whereas Population mean is 3.

\begin{tabular}{|l|l|l|l|l|l|}
\hline \multicolumn{1}{|c|}{ Parameters } & Mean & Median & Mode & Std. Deviation & Z value \\
\hline HR planning & 2.41 & 2.50 & 2.00 & 0.565 & -14.847 \\
\hline Selection and Staffing & 3.06 & 3.00 & 3.50 & 0.740 & -2.947 \\
\hline Training and Development & 2.71 & 2.75 & 2.25 & 0.717 & -7.526 \\
\hline Organization/Job Design & 2.77 & 2.75 & 3.00 & 0.820 & -5.787 \\
\hline Compensation Benefits & 3.25 & 3.37 & 3.00 & 0.742 & 0.034 \\
\hline Union / Labour Relations & 3.30 & 3.50 & 3.50 & 0.687 & 0.800 \\
\hline Employee Communication & 2.93 & 3.00 & 3.50 & 0.781 & -4.000 \\
\hline Employee Assistance & 3.04 & 3.00 & 3.00 & 0.565 & -3.671 \\
\hline Employee Involvement & 2.48 & 2.50 & 3.00 & 0.682 & -11.286 \\
\hline
\end{tabular}

\section{Interpretation}

Table 1: Measure of Central tendency and Computed Z-Value

The SMEs at Central India follows some HR practices in the organization such as Selection and Staffing processes, Compensation Benefits given to the employees, formation of Union/Labour relations and assisting the employees to some extent. Whereas, the other HR practices not followed by the SMEs is Human Resource Planning with the mean 2.41, Training and Development with 2.71, Organization Design with 2.77, Communication with the employees with 2.93 and Involvement of the Employees at workplace with 2.48.

\section{Conclusion}

It is concluded that the management lack systematic formulation which is evident from researcher's survey. The need of Human Resource Planning is realized during the festive season but it is ignore due to the dependence upon labour contracts. For the process of recruitment and selection non-scientific methods are followed by the sample organizations. For selecting an employee SMEs often abstain themselves, majorly the recruitment done from family, staff and friends. There is no provision for Training and Development policies followed. There is no specific assistance given, the employees were left to work at their own ways. Only few organizations are ISO certified and no other documents are there to tell the exact responsibility to the organizations position. Compensation and benefits given mostly on the basis of performance based incentives. Trade unions (TU) are present in few organizations because of their belief that the activities made by TU reduce production and leads to accidents in the organization, but the actual reason is festive season and harvesting season. Large communication gap is recognized between the employees and the employers. No suggestion boxes and news letter was found as they considered taking suggestion from employees is wastage of time. No assistance provided to the employees for their work. They are expected to come on duties on time, perform their jobs, go home and come back again. Worker's Participation Management is non-existing in the sample organizations. Therefore it is concluded that the SMEs at Central India not follow the HR practices in the organizations.

\section{References}

1. SMEs Role in Indian Manufacturing- https://www.ibef.org/download/SMEs-Role-in-IndianManufacturing.pdf (1-sept-2018)

2. Human Resource Management Practices at Small-and-Medium enterprises at Egypthttps:/www.tandfonline.com/doi/abs/10.1080/15475778.2014.929924? $\mathrm{src}=$ recsys\&journalCode=wtnm20 (4-sept-2018)

3. Human Resource Management Practices In India - https://www.ukessays.com/essays/business/humanresource-management-practices-in-india-business-essay.php (5-sept-2018)

4. SMEs $\quad$ Role at $\quad$ India's http://expressindia.indianexpress.com/fe/daily/19980909/25255774.html (7-sept-2018)

5. SME chamber of India- www.smechamberofindia.com (18-sept-2018) 